\title{
The determinants of exclusive breastfeeding in Cameroon, Sub-Saharan Africa
}

\author{
Betrand A Tambe ${ }^{1,2 *}$, Celine S B Mimboe ${ }^{1}$, Julie A Nchung ${ }^{3}$, Christian B Bakwo ${ }^{1}$, Emilienne C Nyobe ${ }^{1}$, Nanfack Pauline ${ }^{1}$ and Dapi Nzefa \\ Leonie $^{4,5}$ \\ ${ }^{1}$ Institute of Medical Research and Plant Medical studies, Yaoundé-Cameroon \\ ${ }^{2}$ Wealth Creation Foundation (WCF), Yaoundé-Cameroon \\ ${ }^{3}$ Facilty of Health Science, University of Buea, Buea-Cameroon \\ ${ }^{4}$ Faculty of Medicine and Biomedical Sciences, Department of Public Health Yaoundé University- Cameroon \\ ${ }^{5}$ Faculty of Social Sciences, Department of Social Work, Linnaeus University, Sweden
}

\begin{abstract}
Background: Breastfeeding provides infants with superior nutritional content that is capable of improving infant immunity and possible reduction in future health care spending. But, majority of infants are not exclusively breastfed as recommended by World Health Organization. The goal of the study was to determine the constraints of exclusive breastfeeding practices among mothers in Efoulan District, Cameroon.
\end{abstract}

Methods: This hospital-based cross-sectional study was conducted among 250 mothers with under-six months infants during postnatal consultation in three public health structures located in the Efoulan health district of Yaounde. Data collection was done using a pretested, interview-led questionnaire. Multivariable logistic regression models that adjusted for confounders were conducted to determinants of breastfeeding initiation (colostrums intake) and exclusive breastfeeding (EBF) in the study area.

Results: The rate of colostrums intake among the subjects was 88.8\% [95\% CI 84.2-92.4\%] while only 45.2\% [95\% CI 38.9-51.6\%] of under 6 months infants were exclusively breastfed for 6 months. After adjusting for potential confounders, multivariable analyses revealed four risk factors of colustrum intake: marital status $(\mathrm{AOR}=4.13,95 \% \mathrm{CI}=1.01-16.86)$, mothers' poor knowledge of diarrhoea ( $\mathrm{AOR}=0.02,95 \% \mathrm{CI}=0.00-0.11)$, household income level $(\mathrm{AOR}=3.42,95 \%$ $\mathrm{CI}=1.43-8.19)$ and increased maternal age $(\mathrm{AOR}=0.29,95 \% \mathrm{CI}=0.08-1.04)$. Also, marital status (AOR=0.16, 95\% CI=0.08-0.31), mothers' poor knowledge of diarrhoea $(A O R=3.05,95 \% \mathrm{CI}=1.21-7.71)$, increased maternal age $(\mathrm{AOR}=1.21,95 \% \mathrm{CI}=1.12-1.30)$ and sex of index infants $(\mathrm{AOR}=1.80,95 \% \mathrm{CI}=1.00-3.22)$ were determinants of EBF in the study area.

Conclusion: The study recommends that efforts should be invested on improving maternal level of education, income, nutritional counselling and access to maternal health services in order to significantly increase the rate of exclusive breastfeeding and to attain the third Sustainable Development Goal.

\begin{abstract}
Abbreviations: CI: Confidence interval; EBF: Exclusive breastfeeding; AOR: Adjusted Odds ratio; SD: Standard deviation; IYCF: Infant and Young Child Feeding
\end{abstract}

\section{Introduction}

Breast milk is the most important and safe food for infants [1,2]. Breastfeeding provides babies with superior nutritional content that is capable of improving their immunity and possibly reduce future health care spending [3-5]. Avoiding colostrum which reinforces immune system and giving some pre-lacteal feed and bottle feeding are contributory factors for preventable diseases which ultimately lead to high infant mortality [6].

Over $85 \%$ of mothers globally do not implement World Health Organisation (WHO) breastfeeding recommendation with only $42 \%$ (57 million) initiating breastfeeding within the first hour after birth, about $35-36 \%$ of babies less than four months are exclusively breastfed and $58 \%$ continue breastfeeding up to the age of two years [7-9]. Previous study data reveal that most mothers started to exclusively breastfeed their infants at birth and the rate decreased significantly about two or more months later [10-13]. Approximately half of the
10 million deaths of infants under 5 years old yearly are due to direct or indirect consequences of malnutrition and a greater proportion of these deaths are linked with improper breastfeeding practices $[7,13]$.

Breastfeeding rates vary both between and within countries. In Cameroon, preceding studies have shown that between 18-20 percent of infants are exclusively breastfed for the first six months after birth [14]. Paucity of published data exists regarding exclusive breastfeeding determinants in Cameroon. The study conducted to identify determinants of exclusive breastfeeding in a group of motherinfant pairs attending postnatal consultation at Efoulan Health District in Yaounde, centre region of Cameroon.

*Correspondence to: Betrand A Tambe, Institute of Medical Research and Plant Medical studies, Yaoundé-Cameroon, Tel: +237674615608; E-mail: ayuk. betrand@yahoo.com

Key words: infant, determinants, exclusive breastfeeding, Cameroon, SubSaharan Africa

Received: December 01, 2018; Accepted: December 10, 2018; Published: December 12, 2018 


\section{Methods}

\section{Research design and study setting}

This was a cross-sectional study conducted in Efoulan Health District in Yaounde, centre region of Cameroon involving 250 motherinfant pairs with infants under 6 months attending public health facilities for postnatal consultation over three months in 2016.

\section{Questionnaire}

A well-structured, pre-tested interview-led questionnaire was used to collect information from the mothers. The pretested questionnaire consisted of 35 questions used to obtain demographic information such as mother's age, father's and mother's employment, maternal education level and information about the infant's age, mode of delivery, birth order and family size. The survey also collected data about different feeding practices, such as whether the mother gave their infants colostrums, where the mothers introduced prelacteal feeds and when solid and liquid supplements were introduced. Mothers were asked the reason that for not exclusively breastfeeding their infants if applicable and their knowledge of diarrhoea were also evaluated.

Reliability and validity of the questionnaire were guaranteed through discussion with experts and by intensive review of relevant literatures. The questionnaire was administered by the researchers themselves with the assistance of the health facility nurses. We defined exclusive breastfeeding as child receiving only breast milk and no additional liquids or solids, with the exception of vitamins, minerals supplements or medications within a period of 4-6 months. The EBF rate was calculated according to the WHO recommendation definition of this key Infant and Young Child Feeding (IYCF) indicator [15] and proposes more categorisation of EBF indicator for the following age ranges $0-3$ and 4-6 months of age.

\section{Sampling technique and sample size}

A multi-stage cluster sampling technique was used to collect data from mothers of index infant under 6 months. In the first stage cluster sampling, a list of the public health facilities located within the Efoulan district was obtained and enumerated with three health facility chosen using simple random sampling to get the primary sampling unit. The sample size was allocated to health facilities, proportional to the size of their population. Then, universal sampling was used to recruit all eligible mothers (15-49 years) of index infant under 6 months as they visit the selected health facilities for the postnatal consultation during the study period. Only those mothers who accepted to participate in the study were recruited for the study.

The study sample size was estimated based on the prevalence of $\mathrm{EBF}$ in Cameroon. The sample size was calculated using the formula $\mathrm{n}=\mathrm{Z}^{2} \times \mathrm{PQ} / \mathrm{d}^{2}$, where $\mathrm{n}$ stands the estimated sample size, $\mathrm{Z}$ is the normal standard deviate, whose value at $95.0 \%$ confidence level is 1.96 , $\mathrm{P}=$ prevalence of EBF; 0.20 [13], $\mathrm{Q}=1-\mathrm{P}=0.80$, and $\mathrm{d}=$ the set margin of error; 0.05 . Therefore, the minimum sample size, $\mathrm{n}=225.4$ or $\mathrm{n} \approx 226$ mothers. Extra $10 \%$ participants were added for any possible nonresponse. The final sample size was 250 mothers.

\section{Data analysis}

The filled questionnaires were checked for completeness, coded, entered into a Microsoft excel spreadsheet and exported to Epi Info 7 for analysis. Data from questionnaires were double entered and merged to check for data entry errors. Categorical variables were summarized as counts and percentage whilst continuous variables were summarized as means and standard deviations. The median age of infants at termination of EBF was estimated. This data was also displayed as tables and graphs. The impact of each variable on the colostrums intake and cessation of breastfeeding was assessed using univariable analysis model to give a measure of the impact of each variable on the exact probabilities of the colostrums intake and cessation of breastfeeding (dependent variables) in the absence of the control for other variables or perceived determinants of breastfeeding (other independent variables).

All variables with a $\mathrm{P}$-value $\leq 0.25$ in univariable analyses and other variables proven by preceding studies to affect breastfeeding were entered spontaneously in the multivariable model. We used a backward stepwise mode in order to avoid excluding non-significant variables that affected the model fitness. We made sure at no point of our analysis did the number of independent variables exceeded 10 variables as recommendations by Altman [16]. The variables with $\mathrm{P}$-value $<0.05$ were considered as determinants factors significantly associated with colostrums intake and exclusive breastfeeding.

\section{Results}

The mean age of the 250 mothers who participated in the study was 27 years and $84.8 \%$ of mothers/caregivers completed secondary or higher level of education. One hundred and twenty-two (52.8\%) of mothers were employed in the last 12 months. About $60.4 \%$ of mothers made more than one antenatal visit when pregnant as compared to $49.6 \%$ of mothers that had a postnatal check-up after 6 weeks. The analysis also showed that the distribution of female and male children was almost equally distributed. The mean age of the children who participated in the study was approximately 4 months. Majority (58.4\%) of children were between 4-6 months old and the remaining $41.6 \%$ were between $0-3$ months of age. Less than half of the mothers were married (40.8\%) and Christian religion (89.2\%). The mean number of children given birth by each mother was 2 .

\section{Exclusive breast feeding (EBF) rate}

Majority $88.8 \%$ [95\% CI $84.2 \%-92.4 \%$ ] of children of surveyed had consumed colostrums within the early days of life. The prevalence of exclusive breastfeeding was $45.2 \%$ [95\% CI 38.9\%-51.6\%] among under 6 months at the moment of the study. Lack of or insufficient breast milk was common reason stated by mothers for the nonpractice of exclusive breastfeeding while less common reasons included amongst others breast milk being dirty and the mother being sick. Exclusive breastfeeding significantly associated with colostrums intake $(\mathrm{P}=0.0002)$.

\section{Univariable analysis}

Table 1 below shows the estimated percentages of colostrums intake and exclusive breastfeeding by hypothesized risk factors. The analysis shows that rate of colostrums intake were statistically significant with mothers' level of education, knowledge of diarrhea, monthly income and religion affiliation. The study analysis also revealed that exclusive breastfeeding was significantly associated with marital status, maternal level of formal education, mothers' age and sex of the child as shown in table 1 .

\section{Multivariable analysis}

A multivariable logistic regression analysis was also done to determine the strength of association between dependent variables (colostrums and EBF) and independent variables (risk factors). As predicted, married mothers had a statistically significant association 
Table 1. Univariable analysis of factors affecting exclusive breastfeeding in Efoulan Health District of Cameroon $(\mathrm{N}=250)$

\begin{tabular}{|c|c|c|c|c|c|c|c|c|}
\hline \multirow[t]{2}{*}{ Characteristics } & \multicolumn{4}{|c|}{ Gave colostrums } & \multicolumn{4}{|c|}{$\begin{array}{c}\text { Agreed to breastfeed or already breastfeeding for exclusively for } 6 \\
\text { months }\end{array}$} \\
\hline & Yes Y (\%) & No N (\%) & $\begin{array}{l}\text { Unadjusted Odd } \\
\text { ratio }(95 \% \mathrm{CI})\end{array}$ & (P-Value) & Yes Y $(\%)$ & No N (\%) & $\begin{array}{l}\text { Unadjusted Odd } \\
\text { ratio }(95 \% \mathrm{CI})\end{array}$ & (P-Value) \\
\hline \multicolumn{9}{|l|}{ Marital status } \\
\hline Single & $129(87.2)$ & $19(12.8)$ & 1 & \multirow[b]{2}{*}{0.325} & $87(58.8)$ & $61(41.2)$ & & \multirow[b]{2}{*}{$0.000^{*}$} \\
\hline Married & $93(91.2)$ & $9(8.8)$ & $\begin{array}{c}1.5 \\
(0.66-3.51)\end{array}$ & & $26(25.5)$ & $76(74.5)$ & $\begin{array}{c}0.24 \\
(0.14-0.42)\end{array}$ & \\
\hline \multicolumn{9}{|c|}{ Maternal level of formal education (years) } \\
\hline $\begin{array}{l}\text { Primary level or less } \\
\text { (Illiterate) }\end{array}$ & $13(46.4)$ & $15(53.6)$ & 1 & \multirow{2}{*}{$0.0000^{*}$} & $123(89.8)$ & $14(10.2)$ & 1 & \multirow{2}{*}{$0.0178^{*}$} \\
\hline $\begin{array}{l}\text { Secondary level or more } \\
\text { (Literate) }\end{array}$ & $199(89.6)$ & $23(10.4)$ & $\begin{array}{c}9.98 \\
(4.23-23.57)\end{array}$ & & $89(78.8)$ & $24(21.2)$ & $\begin{array}{c}0.42 \\
(0.21-0.86)\end{array}$ & \\
\hline \multicolumn{9}{|c|}{ Have 3-4 times watery stool a day } \\
\hline Yes & $63(94.0)$ & 4 & 1 & \multirow[b]{2}{*}{0.2312} & $81(44.3)$ & $102(55.7)$ & 1 & \multirow[b]{2}{*}{0.6226} \\
\hline No & $159(86.9)$ & $24(13.1)$ & $\begin{array}{c}2.38 \\
(0.79-7.13)\end{array}$ & & $32(47.8)$ & $35(52.2)$ & $\begin{array}{c}1.15 \\
(0.66-2.02)\end{array}$ & \\
\hline \multicolumn{9}{|l|}{ Knowledge of diarrhea } \\
\hline Yes & $208(94.1)$ & $13(5.9 .0)$ & 1 & \multirow[b]{2}{*}{$\mathbf{0}$} & $97(43.9)$ & $124(56.1)$ & 1 & \multirow[b]{2}{*}{0.2539} \\
\hline No & $14(48.3)$ & $15(51.7)$ & $\begin{array}{c}0.02 \\
(0.02-0.15)\end{array}$ & & $16(55.2)$ & $13(44.8)$ & $\begin{array}{c}1.57 \\
(0.72-3.43)\end{array}$ & \\
\hline \multicolumn{9}{|l|}{ Monthly salary (FCFA) } \\
\hline$<50,000$ & $24(72.7)$ & $9(72.3)$ & 1 & \multirow[b]{2}{*}{$0.0030 *$} & $19(57.6)$ & $14(42.4)$ & 1 & \multirow[b]{2}{*}{0.1286} \\
\hline $50,000-500,000$ & $198(91.2)$ & $19(8.8)$ & $\begin{array}{c}3.91 \\
(1.59-9.60)\end{array}$ & & $94(43.3)$ & $123(56.7)$ & $\begin{array}{c}0.56 \\
(0.27-1.18)\end{array}$ & \\
\hline \multicolumn{9}{|l|}{ Religious affiliation } \\
\hline Christian & $201(90.1)$ & $22(9.9)$ & 1 & & $100(44.8)$ & $123(55.2)$ & 1 & \\
\hline Muslim & $13(68.4)$ & $6(31.6)$ & $\begin{array}{c}0.24 \\
(0.08-0.69)\end{array}$ & $0.0080^{*}$ & $5(26.3)$ & $14(73.7)$ & $\begin{array}{c}0.44 \\
(0.15-1.26)\end{array}$ & 0.1263 \\
\hline Traditional believe & $8(100.0)$ & $0(0.0)$ & $\begin{array}{c}170748.54 \\
(0.00->1.0 \mathrm{E} 12)\end{array}$ & 0.9641 & $8(100.0)$ & $0(0.0)$ & $\begin{array}{c}1841190 \\
(0.00->1.0 \mathrm{E} 12)\end{array}$ & 0.9562 \\
\hline \multicolumn{9}{|l|}{ Sex of the index infant } \\
\hline Male & $106(89.8)$ & $12(10.2)$ & $\begin{array}{c}0.82 \\
(0.37-1.81)\end{array}$ & \multirow{2}{*}{0.6256} & $41(34.7)$ & $77(65.3)$ & 1 & \multirow{2}{*}{$0.0018^{\star}$} \\
\hline Female & $116(87.9)$ & $16(12.1)$ & & & $72(54.5)$ & $60(45.5)$ & $\begin{array}{c}2.25 \\
(1.25-3.76)\end{array}$ & \\
\hline \multicolumn{9}{|l|}{ Maternal age } \\
\hline $16-25$ & $100(87.0)$ & $15(13.0)$ & 1 & \multirow[b]{2}{*}{0.3952} & $40(34.8)$ & $75(65.2)$ & 1 & \multirow[b]{2}{*}{$0.0024^{*}$} \\
\hline 26-38 & $122(90.4)$ & $13(9.6)$ & $\begin{array}{c}1.41 \\
(0.64-3.10)\end{array}$ & & $73(54.1)$ & $62(45.9)$ & $\begin{array}{c}2.21 \\
(1.32-3.68)\end{array}$ & \\
\hline \multicolumn{9}{|l|}{ Mode of delivery } \\
\hline Vagina & $217(89.3)$ & $26(10.7)$ & 1 & \multirow[b]{2}{*}{0.1619} & $109(44.9)$ & $134(55.1)$ & 1 & \\
\hline Caesarean & $5(71.4)$ & $2(28.6)$ & $\begin{array}{c}0.30 \\
(0.55-1.62)\end{array}$ & & $4(57.1)$ & $3(42.9)$ & $\begin{array}{c}1.64 \\
(0.36-7.48)\end{array}$ & 0.523 \\
\hline Age group & & & & & & & & \\
\hline $0-3$ & $92(88.5)$ & $12(11.5)$ & 1 & & $45(43.3)$ & $59(56.7)$ & 1 & \\
\hline $4-6$ & $130(89.0)$ & $16(11.0)$ & $\begin{array}{c}1.06 \\
(0.48-2.35)\end{array}$ & 0.8861 & $68(46.6)$ & $78(53.4)$ & $\begin{array}{c}1.14 \\
(0.69-1.90)\end{array}$ & 0.6047 \\
\hline Parity & & & & & & & & \\
\hline Primiparous & $82(87.2)$ & $12(12.8)$ & 1 & & $43(45.7)$ & $51(54.3)$ & 1 & \\
\hline Multiparous & $140(89.7)$ & $16(10.3)$ & $\begin{array}{c}1.28 \\
(0.58-2.84)\end{array}$ & 0.543 & $70(44.9)$ & $86(55.1)$ & $\begin{array}{c}0.97 \\
(0.58-1.61)\end{array}$ & 0.8931 \\
\hline
\end{tabular}

*Statistically significant at $P$ value $<0.05$

with higher breastfeeding initiation $(\mathrm{AOR}=4.13,95 \% \mathrm{CI}=1.01-16.86)$. Mothers' poor knowledge of diarrhoea was associated with significant less breastfeeding initiation $(\mathrm{AOR}=0.02,95 \% \mathrm{CI}=0.00-0.11)$. Children born from rich homes had a higher odd of consuming colostrums than children born from poor homes ( $\mathrm{AOR}=3.42,95 \% \mathrm{CI}=1.43-8.19$ ). Increased maternal age was significant with less breastfeeding initiation $(\mathrm{AOR}=0.29,95 \% \mathrm{CI}=0.08-1.04)$.

Analysis also revealed that married mothers had lower odd for EBF than mothers who were single $(\mathrm{AOR}=0.16,95 \% \mathrm{CI}=0.08-0.31)$. Mothers' poor knowledge of diarrhoea was associated with significant high rate of exclusive breastfeeding $(\mathrm{AOR}=3.05,95 \% \mathrm{CI}=1.21-7.71)$. Detail analysis revealed than female infants were more likely to be EBF as compared to male infants $(\mathrm{AOR}=1.80,95 \% \mathrm{CI}=1.00-3.22)$ while increasing maternal age was significant with more $\mathrm{EBF}(\mathrm{AOR}=1.21$, 95\% CI=1.12-1.30) (Table 2).

\section{Discussion}

Our findings revealed that, even though there were high rates of colostrums intake, EBF rate was low in Cameroon which calls for concern. These rates are below the targeted rates of $90 \%$ exclusive 
Table 2. Multivariable analysis of factors affecting exclusive breastfeeding in Efoulan Health District of Cameroon $(\mathrm{N}=250)$

\begin{tabular}{|c|c|c|c|c|}
\hline \multirow{2}{*}{ Characteristics } & \multicolumn{2}{|c|}{ Gave colostrums } & \multicolumn{2}{|c|}{$\begin{array}{l}\text { Agreed to breastfeed or already breastfeeding for exclusively for } 6 \\
\text { months }\end{array}$} \\
\hline & $\begin{array}{c}\text { Adjusted } \\
\text { Odd ratio }(95 \% \mathrm{CI})\end{array}$ & (P-Value) & $\begin{array}{c}\text { Adjusted } \\
\text { Odd ratio }(95 \% \mathrm{CI})\end{array}$ & (P-Value) \\
\hline \multicolumn{5}{|l|}{ Marital status } \\
\hline Single & 1 & \multirow{2}{*}{$0.0484^{*}$} & 1 & \multirow{2}{*}{$0.0000^{*}$} \\
\hline Married & $4.13(1.01-16.86)$ & & $0.16(0.08-0.31)$ & \\
\hline \multicolumn{5}{|c|}{ Knowledge of diarrhoea } \\
\hline Yes & 1 & \multirow{2}{*}{$0.0000^{*}$} & 1 & \multirow{2}{*}{$\mathbf{0 . 0 1 8 2}^{*}$} \\
\hline No & $0.02(0.00-0.11)$ & & $3.05(1.21-7.71)$ & \\
\hline \multicolumn{5}{|c|}{ Monthly salary (FCFA) } \\
\hline$<50,000$ & 1 & \multirow{2}{*}{$0.0059^{*}$} & 1 & \multirow{2}{*}{0.1865} \\
\hline $50,000-500,000$ & $3.42(1.43-8.19)$ & & $0.52(0.20-1.37)$ & \\
\hline \multicolumn{5}{|c|}{ Sex of index infant } \\
\hline Male & 1 & \multirow{2}{*}{0.6104} & 1 & \multirow{2}{*}{$0.0493^{*}$} \\
\hline Female & $0.81(0.36-1.81)$ & & $1.80(1.00-3.22)$ & \\
\hline \multicolumn{5}{|l|}{ Maternal age } \\
\hline $16-25$ & 1 & \multirow{2}{*}{$0.0574^{*}$} & 1 & \multirow{2}{*}{$0.0000^{*}$} \\
\hline 26-38 & $0.29(0.08-1.04)$ & & $1.21(1.12-1.30)$ & \\
\hline
\end{tabular}

*Statistically significant at $P$ value $<0.05$

breastfeeding of children under 6 months of age by mothers which is associated with $10 \%$ reduction of infant deaths [5]. The determinant of colostrums and EBF are numerous and complex affecting in different ways in diverse situations. The main risk factors found to be significantly associated with colostrums intake in the final model of our analysis include mother's marital status, poor knowledge of diarrhoea, household monthly income and increase maternal age. In addition, the study also made known that marital status of the mothers, Mothers' poor knowledge of diarrhoea, the sex of the index child and the age of the mother had a statistically significant association with EBF after adjusting for potential confounders.

Two hundred and twenty-two (88.8\%) of the children surveyed had consumed colostrums within the early days of life. A comparative study conducted by Dun-Dery and Laar [6] reported that most (91\%) of the study participants-initiated breastfeeding within the first hour after delivery. This corroborates with findings by Heck in his study to assess the socioeconomic status and breastfeeding initiation among California mothers revealed a high breastfeeding initiation rate (95.2\%) among working mothers within one hour after birth [17-19], contrary to findings reported by Liben \& Yesuf revealed 39.6\% breastfeeding initiation rate among working mothers in Ethiopia [18]. The significance of early breastfeeding initiation is well documented $[18,20]$.

The prevalence of exclusive breastfeeding among under 6 months was $45.2 \%$ at the moment of the study. Similar prevalent rate of $40 \%$ has also been registered in a study conducted to assess the determinants of breastfeeding in neighbouring Nigeria [21]. The rate is greater than the Cameroon rate (20\%) [13] and lower as compared to prevalence rate in Ethiopia that had $63 \%$ of infants that stay on EBF for the first 5 months in the study [22]. The reason might be because the study participants were health conscious mothers attending postnatal consultation.

Study findings showed a significant association between exclusive breastfeeding and colostrums intake. This finding confirms the results of a study conducted by Ludvigsson [23] in Bolivia that revealed that both avoidance of prelacteal feeding and use of colostrums seem to be associated with improved breastfeeding patterns.

Mothers from socioeconomically privileged households were likely to initiate breastfeeding than those from lower socioeconomic homes in the present study. Our findings indicated an association between household wealth and breastfeeding initiation, with $52.2 \%$ of mothers initiating breastfeeding from poor households with low education levels compared to those from rich households with secondary education or higher $(94.0 \%)$. Children born into poverty are almost twice as likely to die before the age of five as those from wealthier families. The findings are consistent with preceding studies that showed that mothers from socioeconomically higher class were more likely to carry out exclusive breastfeeding than those from lower socioeconomic class [24,25]. Mothers with high income levels might have better education level, easier access to media and health services which might have augmented their level of awareness and made them relatively more aware about EBF. Furthermore, mothers' poor knowledge of diarrhoea was significantly associated with less breastfeeding initiation. Also, this study found an association between maternal education and initiation of breastfeeding in the univariable analysis but this association disappeared when other variables were included in the model. Nevertheless, review of eleven studies reported an association between maternal education and duration of EBF, and the majority found that mothers with lower educational levels were at a higher risk of discontinuing EBF [26]. Maternal age was significantly associated with both initiation and exclusive breastfeeding in the current study. This association has earlier been reported by Chudasama, et al [27].

As expected, female infants were more likely to be EBF comparable to previous studies that revealed that boys were more likely to be introduced to complementary feeding earlier compared with girls. Anecdotal evidence indicates that boys are introduced to complementary foods early because breast milk alone does not meet their feeding demands [28-31]. As predicted also, married mothers were more likely to initiate breastfeeding but less likely to exclusively breastfeed their infants. Similarly, marital status has been reported in earlier studies conducted in Ghana, India and Peru to be significantly associated with exclusive breastfeeding [32,33].

When interpreting the results, the following limitations should be noted. Firstly, the possibility of self-selection bias among healthconscious participants who volunteer for this study. This bias may be particularly high among the older infants, who might have been brought to the hospital because of ill-health and were possibly less 
likely to be breast-fed. Secondly, recall bias or social desirability bias due to the retrospective nature of the data collection, might have affected the estimation of the stated breastfeeding practices. Thirdly, the small sample size used in the present study may have restricted variables from being statistically associated with the practice of exclusive breastfeeding in the final model of the analysis.

However, the present study is among the first to examine the constraints of the breastfeeding pattern in Cameroon. The use of both interview-led questionnaire and few well-trained interviewers to collect data increased the consistency of interview management and interpretation of the participants' responses.

\section{Conclusion}

Prevalence of exclusive breastfeeding practice in Efoulan health district of Yaoundé was lower than the WHO recommendations. The marital status, maternal educational level, income level, sex of the index child and increasing maternal age were noted to influence the rate of initiation and EBF in the area of study, accounted for the discrepancy between the actual and the desired EBF rate. Also, efforts should be invested on improving maternal level of education, income, nutritional counseling and access to maternal health services in order to significantly increase the rate of exclusive breastfeeding and to attain the third Sustainable Development Goal.

\section{Acknowledgements}

The authors would like to thank colleagues of Laboratory for Epidemiological Research of Centre for Food and Nutrition Research (CRAN)-IMPM for their contributions in the study which was highly appreciated.

\section{Authors' contributions}

BAT drafted the manuscript. All authors contributed in data collection and analysis, writing and approval of the final manuscript before submissions.

\section{Ethics approval and consent to participate}

The protocol was approved by the Centre Regional Ethics Committee for Human Health Research and administrative authorization obtained from respective health institutions. Informed written consent was solicited and obtained from all participants after satisfactory explanation of the research objectives. Confidentiality of participants was ensured through the coding of questionnaires and adhering to the declaration of Helsinki.

\section{Consent for publication}

Not applicable.

\section{Competing interests}

No conflict of interest was declared by the authors.

\section{References}

1. Kramer MS, Kakuma R (2004) The optimal duration of exclusive breastfeeding: a systematic review, World Health Organisation. Adv Exp Med Biol 554: 63-77.

2. Mananga MJ, Kana-Sop MM, Nolla NP, Tetanye-Ekoe, Gouado I (2014) Feeding Practices Food and Nutrition Insecurity of infants and their Mothers in Bangang Rural Community, Cameroon. J Nutr Food Sci 4: 264.

3. World Health Organization (2001) Infant and young child nutrition: Global strategy for infant and young child feeding.
4. UNICEF (2006) Progress for children: A report card on Nutrition.

5. Jones G, Steketee R, Black R, Bhutta Z, Morris S (2003) The bellagio child survival study group: How many child deaths can we prevent this year? Lancet 362: 65-71.

6. Iqbal SMJ, Afzal MF, Azhar IH, Sultan MS (2010) First Feed in Newborn: are We Following WHO Recommendations? Ann King Edw Med Univ 16: 229-232.

7. World Health Organization (2003) Global strategy for infant and young child feeding. World Health Organization, Geneva.

8. Iellamo A, Sobel H, Engelhardt K (2015) Working mothers of the world health organization Western Pacific Offices: lessons and experiences to protect, promote, and support breastfeeding. J Hum Lact 31: 36-39.

9. Mangasaryan N, Martin L, Brownlee A, Ogunlade A, Rudert C, et al. (2012) Breastfeeding promotion, support and protection: Review of six country programmes. J Nutr 7: 990-1014.

10. Qasem W, Fenton T, Friel J (2015) Age of introduction of first complementary feeding for infants: a systematic review. BMC Pediatr 15: 107. [Crossref]

11. Mascarenhas ML, Albernaz EP, Silva MB, Silveira RB (2006) Prevalence of exclusive breastfeeding and its determiners in the first 3 months of life in the South of Brazil. $J$ Pediatr (Rio J) 82: 289-294. [Crossref]

12. Horta BL, Bahl R, Martines JC, Victora CG (2007) Evidence on the long term effects of breastfeeding. Systematic reviews and meta analyses. WHO, Geneva.

13. United Nations Children's Fund (2007) The State of the World's Children 2008: Child Survival. United Nations Children's Fund, New York.

14. World Health Organization (2013) http://apps.who.int/gho/data/view.main. NUT1730?lang=en

15. World Health Organization: Indicators for assessing infant and young child feeding practices. Washington DC, USA: WHO, 2008.

16. Giuliano KK, Scott SS, Elliot S, Giuliano AJ (1999) Temperature measurement in critically ill orally intubated adults: a comparison of pulmonary artery core, tympanic, and oral methods. Crit Care Med 27: 2188-2193. [Crossref]

17. Dun-Dery EJ, Laar AK (2016) Exclusive breastfeeding among city-dwelling professional working mothers in Ghana. Int Breastfeed $J$ 11: 23.

18. Heck KE (2006) Socioeconomic status and breastfeeding initiation among California Mothers. Public Health Rep 121: 51-59.

19. Liben ML, Yesuf EM (2016) Determinants of early initiation of breastfeeding in Amibara district, Northeastern Ethiopia: a community based cross-sectional study. Int Breastfeed J 11: 7 .

20. Black R, Allan LH, Bhutta ZA, Caulfield LE, de Onis M, et al. (2008) The materna and child undernutrition study group. Maternal and child undernutrition: global and regional exposures and health consequences. Lancet 371: 243-260.

21. Agho KE, Dibley MJ, Odiase JI, Ogbonmwan SM (2011) Determinants of exclusive breastfeeding in Nigeria. BMC Pregnancy Childbirth 11: 2. [Crossref]

22. Yeneabat T, Belachew T, Muluneh H (2014) Determinants of cessation of exclusive breastfeeding in Ankesha Guagusa Woreda, Awi Zone, Northwest Ethiopia: a crosssectional study. BMC Pregnancy and Childbirth 14: 262.

23. Ludvigsson JF (2003) Breastfeeding intentions, patterns, and determinants in infants visiting hospitals in La Paz, Bolivia. BMC Pediatr 3: 5. [Crossref]

24. Blas E, Kurup AS (2010) Equity, social determinants and public health programme. Geneva: World Health Organization.

25. National Institute of Population Research and Training (NIPORT), Mitra and Associates, ORC Macro (2005) Bangladesh Demographic and Health Survey 2004. Dhaka, Bangladesh and Calverton, USA: NIPORT, Mitra and Associates, and ORC Macro.

26. Boccolini CS (2012) Determinantes sociais do aleitamento materno. In PhD thesis. Rio de Janeiro: Fundação Oswaldo Cruz.

27. Chudasama RK, Patel PC, Kavishwar AB (2008) Factors associated with duration of exclusive breastfeeding. Internet J Pediatr Neonatol 9: 1.

28. Gul S, Khalil R, Yousafzai MT, Shoukat F (2014) Newborn care knowledge and practices among mothers attending pediatric outpatient clinic of a hospital in Karachi, Pakistan. Int J Health Sci 8: 167-175.

29. Kesterton AJ, Cleland J (2009) Neonatal care in rural Karnataka: healthy and harmful practices, the potential for change. BMC Pregnancy Childbirth 9: 20. 
30. Raman S, Srinivasan K, Kurpad A, Dwarkanath P, Ritchie J, et al. (2014) 'My mother... my sisters... and my friends': sources of maternal support in the perinatal period in urban India. Midwifery 30: 130-137.

31. Raman S, Srinivasan K, Kurpad A, Razee H, Ritchie J (2014) "Nothing special, everything is maamuli": socio-cultural and family practices influencing the perinata period in urban India. PLoS One 9: e111900.
32. Bahl R, Frost C, Kirkwood BR, Edmond K, Martines J, et al. (2005) Infant feeding patterns and risk of death and hospitalization in the first half of infancy: multicentre cohort study. Bulletin of World Health Organization 83: 418-426.

33. Faruque AS, Ahmed AM, Ahmed T, Islam MM, Hossain MI, et al. (2008) Nutrition: basis for healthy children and mothers in Bangladesh. J Health Popul Nutr 26: 325339. [Crossref]

Copyright: (C2018 Tambe BA. This is an open-access article distributed under the terms of the Creative Commons Attribution License, which permits unrestricted use, distribution, and reproduction in any medium, provided the original author and source are credited. 